\title{
A simple method of face mask resuscitation at birth
}

\author{
E W HOSKYNS, A D MILNER, AND I E HOPKIN
}

Department of Neonatal Medicine and Surgery, City Hospital, Nottingham

SUMmaRY Twenty two infants were resuscitated at birth using a face mask connected to an oxygen supply from a conventional resuscitaire. Intermittent finger occlusion provided the positive pressure within the mask. This method was apparently at least as effective as the best bag and mask systems and was convenient to use.

Resuscitation of infants using a bag and face mask is a well accepted technique and seems empirically to be successful. The essential features to obtain the best results are a round mask, with a compliant ring to form an adequate seal, ${ }^{1}$ a large reservoir to allow a more sustained pressure ${ }^{2}$ with a robust design, and sufficient staff training. Even so the results of Milner et al showed that compared with intubation face mask resuscitation rarely produced volumes adequate for alveolar ventilation and worked mainly by stimulating the baby's own respiratory efforts. ${ }^{3}$ Theoretically, face mask resuscitation is attractive as it is safe, it is easy to learn, and fears about gastric distension have proven groundless. ${ }^{4}$ Studies on intubated babies have shown, however, that tidal exchange can be improved further if the initial inflation pressure can be maintained for at least two seconds. ${ }^{5}$ To achieve this we have mounted the oxygen supply of a conventional resuscitaire into a face mask so that the inflation pressure can be provided by occluding the flow out of the mask. This allows easy control of the duration of inflation and is less cumbersome.

\section{Methods}

Elective and emergency caesarean sections of term babies were attended. Resuscitation was begun if the Apgar score was less than 6 and was associated with apnoea. The Figure shows a diagram of the apparatus. A standard round padded face mask (Ambu) was used with two small holes drilled in the hard perspex portion. One was attached to a pressure transducer (Bell and Howell) to measure the mask pressure, and the other provided a bias flow of air from the resuscitaire with a pressure blow off valve. The set pressure was varied to provide a range of mask pressures up to $30 \mathrm{~cm} \mathrm{H}_{2} \mathrm{O}$. A mercury pneumotachograph was attached to the central hole in the face mask and connected to a differential pressure transducer (SE Labs) to measure expiratory flow. Both pressure and flow signals were amplified and displayed on a two channel Devices pen recorder. Volume was calculated from the area under the flow curve. Positive pressure was provided by occluding the end of the pneumotachograph with a finger. The mask was held firmly to the baby's face and the first inflation was prolonged ( $2-5$ seconds) with subsequent inflations of $0 \cdot 5-1$ seconds at a rate of $30-60$ per minute-that is, standard resuscitation procedure. Resuscitation was then continued as indicated clinically.

\section{Subjects}

Data were obtained from 22 full term infants delivered by caesarean section. Eleven of the 22 were boys, and the mean gestational age was 39 weeks (range 37-41 weeks) and mean birth weight $3280 \mathrm{~g}$ (range $1800-4300 \mathrm{~g}$ ). Most of the babies made an initial cry before an episode of apnoea, but

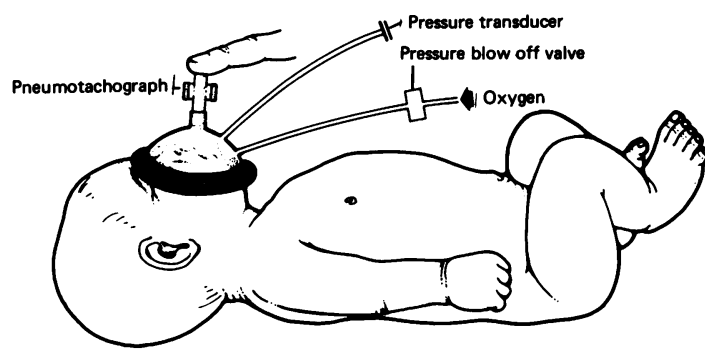

Figure Mask resuscitation and monitoring apparatus. Pressure is applied by occluding the flow outlet of the mask with a finger. 
in four cases there were no respiratory efforts before resuscitation. Eighteen were elective sections, the principal indications being breech presentation (six cases) cephalopelvic disproportion/previous section (six), and placenta praevia (two)). The four emergency sections- that is, performed after the start of the first stage of labour-were for fetal distress (three cases) or failure to progress in labour (one). All the babies studied were normal at the postnatal examination at 24 hours.

\section{Results}

All the babies were successfully resuscitated using this system, except one who required intubation and ventilation for two minutes. This baby had been delivered electively at 39 weeks because of breech presentation. At birth the baby was clinically asphyxiated with an Apgar score of 1 . Face mask resuscitation was started, but the heart rate remained between $50-100$ beats/min and a clinical decision was made to intubate. After intubation the heart rate quickly improved and the subsequent course was uneventful. Subsequent analysis showed that all the expiratory volumes were less than the respiratory dead space.

The anatomical dead space of the respiratory system is $2.2 \mathrm{ml} / \mathrm{kg}$ and is independent of age. ${ }^{6} \mathrm{We}$ defined adequate ventilation as being $4.4 \mathrm{ml} / \mathrm{kg}$ or more-that is, two dead spaces-implying some degree of alveolar ventilation. The proportion of babies needing more than three inflations before onset of spontaneous breathing was small, so the first three inflations were analysed (Table 1). With each inflation $22-32 \%$ of the babies achieved an adequate expiratory volume ( $\geqslant$ two dead spaces). If this is compared with the best bag and mask systems from a previous study using the same recording equipment ${ }^{3}$ the efficacy is similar (Table 2). As a result of the variation in the blow off pressure, however, mean pressure generated was less than

Table 1 Expiratory volumes from the first three inflations during resuscitation

\begin{tabular}{lllll}
\hline \multicolumn{5}{c}{ Inflation } \\
\cline { 2 - 5 } & First & Second & Third & All three \\
\hline $\begin{array}{l}\text { No of patients } \\
\text { Inflation pressure }\end{array}$ & 22 & 22 & 21 & 65 \\
$\begin{array}{l}\left.\text { (cm } \mathrm{H}_{2} \mathrm{O}\right) \\
\text { (Mean (range)) }\end{array}$ & $27 \cdot 5(20-34)$ & $23 \cdot 3(12-32)$ & $23 \cdot 5(15-30)$ & $24 \cdot 4$ \\
Expiratory volume & $($ No of dead spaces): & & \\
$<1$ & 10 & 12 & 12 & 34 \\
$\quad 1$ & 5 & 4 & 4 & 13 \\
$\geqslant 2$ & 7 & 6 & 5 & 18 \\
\hline
\end{tabular}

Table 2 Comparison of bag and mask resuscitation systems with the present study

\begin{tabular}{llll}
\hline & $\begin{array}{c}\text { Present } \\
\text { study }\end{array}$ & Other systems & \\
\cline { 2 - 4 } & & & \multicolumn{1}{c}{$\begin{array}{l}\text { Laerdal }^{*} \\
\text { (paediatric) }\end{array}$} \\
\hline $\begin{array}{l}\text { Mean inflation } \\
\text { pressure }\left(\mathrm{cm} \mathrm{H}_{2} \mathrm{O}\right)\end{array}$ & 24.4 & 26.9 & $30 \cdot 3$ \\
$\begin{array}{l}\text { No (\%) of inflations } \\
\text { achieving adequate } \\
\text { ventilation }\end{array}$ & $18 / 65(28)$ & $12 / 30(40)$ & $6 / 30(20)$ \\
$\begin{array}{l}\text { No (\%) of babies with } \\
\text { at least one } \\
\text { adquate volume in } \\
\text { first three inflations }\end{array}$ & $8 / 22(36)$ & $4 / 10(40)$ & $3 / 10(30)$ \\
\hline
\end{tabular}

${ }^{*}$ Results taken from Field et al. ${ }^{2}$

Table 3 Relation between inflation pressure $\geqslant 25 \mathrm{~cm} \mathrm{H}_{2} \mathrm{O}$ and adequacy $(\geqslant 4.4 \mathrm{ml} / \mathrm{kg})$ of tidal volume

\begin{tabular}{|c|c|c|c|}
\hline & \multicolumn{2}{|c|}{ Expiratory volume } & \multirow[t]{2}{*}{ Total } \\
\hline & $\begin{array}{l}\text { Adequate } \\
(\geqslant 4.4 \mathrm{ml} / \mathrm{kg})\end{array}$ & $\begin{array}{l}\text { Less than } \\
\text { adequate } \\
(<4.4 \mathrm{ml} / \mathrm{kg})\end{array}$ & \\
\hline \multicolumn{4}{|l|}{ Inflation pressure: } \\
\hline$\geqslant 25 \mathrm{~cm} \mathrm{H} \mathrm{H}_{2} \mathrm{O}$ & 14 & 12 & 26 \\
\hline$<25 \mathrm{~cm} \mathrm{H} \mathrm{H}_{2} \mathrm{O}$ & 4 & 35 & 39 \\
\hline Total & 18 & 47 & 65 \\
\hline
\end{tabular}

$\chi^{2}=12 \cdot 7, p<0 \cdot 001$.

with the bag and mask systems. There was a significant relation between adequate expiratory volume and pressure generated in the mask $(z=4.51, p<0.001$, Wilcoxon two sample test $)$, suggesting that the lower pressures used in this study were too low for optimal tidal exchange. This is borne out by the significant increase in adequate expiratory volume with pressures above $25 \mathrm{~cm} \mathrm{H}_{2} \mathrm{O}$ to the extent that the success rate was $54 \%$ above this pressure and $10 \%$ below it (Table 3 ).

The effect of the babies' own respiratory efforts was also examined. In 14 of the 65 inflations the baby made an inspiratory effort, and eight of these were associated with an adequate expiratory volume. This association was significant $\left(\chi^{2}=5 \cdot 97\right.$. $\mathrm{p}<0.02)$. There was also an association between the presence of an inspiratory effort and the mask pressure $(z=2.52, p<0.01$, Wilcoxon two sample test), but not enough to explain all the influence of pressure on adequate volume.

\section{Discussion}

At birth a baby's airways are full of fluid. As tidal ventilation begins some of the inspired gas may form 
an initial functional residual capacity. In this situation inspiratory volume will be larger than expiratory volume. As a result of inevitable leak around the face mask on inflation, it was not possible to measure inspiratory volumes, so the expiratory volumes presented here may underestimate the gas available for respiration. Babies born by caesarean section, however, are much less likely to form a functional residual capacity after the first breath than those delivered vaginally, ${ }^{7}$ and we think this is unlikely to alter our results appreciably.

The pressure applied to the airways depends on the blow off valve, the seal of the mask around the face, and the flow of gas. In view of the correlation between pressure and adequate volume the results with this technique could be improved with consistent inflation pressures of more than $25 \mathrm{~cm} \mathrm{H}_{2} \mathrm{O}$. From a practical point of view this method of resuscitation was found to be convenient and easy to use and it was possible to hold the mask to the baby's face and apply the inflation pressure with one hand, leaving the other free. In units with a resuscitaire it is a cheap, convenient, and effective way of providing a face mask facility.
We are grateful to The Medical Research Council for funding this project.

\section{References}

1 Palme C, Hystrom B, Tunell R. The evaluation of the efficacy of face masks in the resuscitation of newborn infants. Lancet 1985;i:207-10.

2 Field DJ, Milner AD, Hopkin IE. Efficiency of manual resuscitation at birth. Arch Dis Child 1986;61:300-4.

${ }^{3}$ Milner AD, Vyas H, Hopkin IE. Efficacy of face mask resuscitation at birth. Br Med J 1984;289:1563-5.

${ }^{4}$ Vyas H, Milner AD, Hopkin IE. Face mask resuscitation; does it lead to gastric distension? Arch Dis Child 1983;58:373-5.

5 Vyas H, Milner AD, Hopkin IE. Physiological response to prolonged and slow rise inflation. J Pediatr 1981;99:635.

${ }^{6}$ Godfrey S. Scientific foundations of paediatrics. In: Davis J, Dobbing J, eds. Growth of the respiratory system - functional development. London: Heineman, 1974;254-71.

7 Vyas H, Milner AD, Hopkin IE. Intrathoracic pressure and volume changes during spontaneous onset of respiration in babies born by caesarean section and vaginal deliveries. J Pediatr 1981;99:787-91.

Correspondence to Dr E W Hoskyns, Department of Neonatal Medicine and Surgery, City Hospital, Hucknall Road, Nottingham NG5 1PB, England.

Received 12 November 1986 